\title{
Effects of Chronic Ethanol Feeding on Rat Hepatocytic Glutathione Relationship of Cytosolic Glutathione to Efflux and Mitochondrial Sequestration
}

Jose C. Fernandez-Checa, Murad Ookhtens, and Neil Kaplowitz

Liver Research Laboratory, Wadsworth Veterans Administration Medical Center and the UCLA School of Medicine, Los Angeles, California 90073

\begin{abstract}
Chronic ethanol feeding to rats increases the sinusoidal component of hepatic glutathione (GSH) efflux, despite a lower steady-state GSH pool size. In the present studies, no increase of biliary GSH efflux in vivo was found in chronic ethanol-fed cells. Studies were performed on ethanol-fed and pair-fed cells to identify the kinetic parameters of cellular GSH concentration-dependent efflux. The relationship between cytosolic GSH and the rate of efflux was modeled by the Hill equation, revealing a similar $V_{\max }, 0.22 \pm 0.013$ vs. $0.20 \pm 0.014 \mathrm{nmol} / \mathrm{min}$ per $10^{6}$ cells for ethanol-fed and pair-fed cells, respectively, whereas the $K_{\mathrm{m}}$ was significantly decreased $(25.3 \pm 2.3$ vs. $33.5 \pm 1.4 \mathrm{nmol} / 10^{6}$ cells) in ethanol-fed cells. The difference in $K_{m}$ was larger when the data were corrected for the increased water content in ethanol-fed cells. We found a direct correlation between mitochondria and cytosolic GSH, revealing that mitochondria from ethanol-fed cells have less GSH at all cytosolic GSH values. The rate of resynthesis in depleted ethanolfed cells in the presence of methionine and serine was similar to control cells and $\boldsymbol{\gamma}$-glutamylcysteine synthetase remained unaffected by chronic ethanol. However, the reaccumulation of mitochondrial GSH as the cytosolic pool increased was impaired in the ethanol cells. The earliest time change in GSH regulation was a $50 \%$ decrease in the mitochondrial GSH at 2 wk.
\end{abstract}

\section{Introduction}

Glutathione (GSH) plays an important role in antioxidant defense and detoxification of xenobiotics. In hepatocytes, GSH is found in cytosol $(\sim 90 \%)$ and mitochondria $(\sim 10 \%)$. Mitochondrial GSH may play a critical role in cell viability (1). GSH is sequestered in this organelle after synthesis in cytosol by a poorly characterized mechanism (2). Cytosolic GSH undergoes efflux from hepatocytes into bile and blood. The saturability of hepatic GSH efflux and the fact that it can be competitively inhibited by organic anions (3) and methionine $(4,5)$ and transstimulated in sinusoidal enriched-membrane vesicles (6) have suggested that it is a carrier-mediated process.

The pathogenesis of alcoholic liver disease is poorly understood. However, an important factor may be injury as a result of oxidant stress, including lipid peroxidation $(7,8)$. Since GSH plays a critical role in defense against oxidant stress (9), it

Address reprint requests to Dr. Fernandez-Checa, Liver Research Laboratory, W151N, Wadsworth Veterans Administration Hospital, Los Angeles, CA 90073.

Received for publication 24 May 1988 and in revised form 31 October 1988.

The Journal of Clinical Investigation, Inc.

Volume 83, April 1989, 1247-1252 is of importance to determine the influence of ethanol on hepatic GSH homeostasis.

When ethanol was fed chronically to rats for 6-8 wk, we observed several important changes in hepatic GSH homeostasis (10): Cytosolic GSH fell modestly, cellular efflux increased markedly and GSH was diminished to a much greater extent in mitochondria than cytosol. Further insight into the mechanism of these changes and their characterization are the subjects of this report. In our previous studies, efflux of GSH was increased with ethanol feeding despite a somewhat lower cytosolic GSH. Therefore, it was uncertain whether the increased efflux was due to a change in $V_{\max }$ or $K_{\mathrm{m}}$ for transport and whether the lower cytosolic GSH reflected a limited maximal capacity to synthesize GSH. In our current studies, we have varied cytosolic GSH to define the kinetics of efflux from hepatocytes and have related the GSH efflux to the cytosolic GSH (rather than whole-cell GSH) for the first time. In addition, to determine the capacity to synthesize GSH, we have depleted GSH and then compared the rate of its resynthesis in control versus ethanol-fed hepatocytes. To further define the defect in mitochondrial GSH, we have defined the relationship between cytosolic and mitochondrial GSH pool sizes in hepatocytes from chronic ethanol-fed versus control rats by varying the cytosolic GSH over a wide range. In addition, we have defined the temporal sequence in appearance of these changes in GSH homeostasis. Finally, using perfused livers, we have confirmed that the increased cellular GSH efflux is accounted solely by the increase in the sinusoidal component, since the canalicular component was not increased by chronic ethanol consumption.

\section{Methods}

Materials. GSH, collagenase (type IV), bovine serum albumin, diethyl maleate (DEM), ${ }^{1}$ methionine, serine, and Hepes were purchased from Sigma Chemical Co. (St. Louis, MO). NADPH was obtained from United States Biochemical Corp. (Cleveland, $\mathrm{OH}$ ). Cobalt chloride was from Fisher Scientific Co. (Fair Lawn, NJ). L- $(\alpha S-5 S)-\alpha$-amino-3chloro-4,5-dihydro-5-isoxazoleacetic acid (AT-125) was a gift from Ruth Davis, National Cancer Institute, Bethesda, MD. [Carboxyl $-{ }^{14} \mathrm{C}$ ] inulin, $2.4 \mathrm{mCi} / \mathrm{g}$ and ${ }^{3} \mathrm{H}_{2} \mathrm{O}, 250 \mu \mathrm{Ci} / \mathrm{ml}$ were obtained from $\mathrm{New}$ England Nuclear (Boston, MA). The incubations were in modified Fisher's medium, supplemented with methionine, prepared as described previously (10). All other materials used were of reagent quality and were obtained from standard commercial sources.

Animals and diet. Male Sprague-Dawley rats weighing 160-180 g were pair-fed liquid diets (11) (Bioserv, Rahway, NJ) containing 36\% calories as ethanol or an isocaloric mixture with maltose dextrin substituted for ethanol as detailed previously (10). Animals received progressive increases in ethanol during the first week of feeding and were maintained on a reverse light-dark cycle. Experiments were started

1. Abbreviation used in this paper: DEM, diethylmaleate. 
between 9:30 and 10:00 a.m. in overnight-fasted animals. All studies were performed between 6 and 8 wk of feeding unless otherwise noted. Ethanol-fed cells refers to cells isolated from chronic ethanol-fed rats throughout the text.

Treatments to raise and lower GSH. To lower the concentration of GSH in hepatocytes, freshly isolated cells were preincubated with DEM (in DMSO) from 0.04 to $0.8 \mathrm{mM}$ for $15 \mathrm{~min}$ at $37^{\circ} \mathrm{C}$ in KrebsHenseleit buffer, after which cells were washed and resuspended in fresh Krebs buffer.

To raise hepatic GSH concentration above control values, cobalt chloride was used. A single dose of $0.05 \mathrm{~g} / \mathrm{kg}$ in saline was injected subcutaneously in the lower dorsal region the evening before cell isolation in animals receiving $6 \mathrm{wk}$ of feeding. Consequently, cytosolic GSH concentration was raised twofold, from $36.1 \pm 4.8$ to $84.9 \pm 17.3$ $\mathrm{nmol} / 10^{6}$ cells for pair-fed and from $21.5 \pm 6.6$ to $41.3 \pm 4.8 \mathrm{nmol} / 10^{6}$ cells for ethanol-fed cells. The mechanism for the diminished response to cobalt chloride in the ethanol-fed rats has not been further evaluated. Since our previous work $(12,13)$ has shown no adverse effect of cobalt chloride on GSH transport, we assume this is true for the ethanol-fed rats. Since cobalt chloride was ineffective in achieving comparable high cell GSH levels in ethanol-fed hepatocytes, we alternatively preincubated isolated cells without cobalt chloride treatment with 1 $\mathrm{mM}$ methionine and serine in modified Fisher's medium for 2 or for 4 h at $37^{\circ} \mathrm{C}$ under $95 \% \mathrm{O}_{2} / 5 \% \mathrm{CO}_{2}$. Cells were then washed and resuspended in Krebs buffer without methionine and incubated for another $30 \mathrm{~min}$ to study GSH efflux. Samples of cell and medium were collected at $0,5,15$, and $30 \mathrm{~min}$. Efflux was linear over this interval as determined by linear regression. Viability was $\geq 86 \%$ and was no different than the freshly isolated cells.

Hepatocyte isolation and incubation. Hepatocytes were isolated according to the method of Moldeus et al. (14). Viability of cells was determined by trypan blue exclusion $(0.2 \%)$ and was $\geq 90.0 \%$. Cells that were preincubated in vitro with DEM or methionine and serine and that were obtained from animals treated in vivo with cobalt chloride were incubated in $25-\mathrm{ml}$ Erlenmeyer flasks at $37^{\circ} \mathrm{C}$ at a concentration of $1-2 \times 10^{6}$ cells $/ \mathrm{ml}$ in an orbital-shaker bath (10-ml suspension). At indicated times, $1-\mathrm{ml}$ aliquots were removed and spun at $13,000 \mathrm{~g}$ in a microfuge (Beckman Instruments, Inc., Fullerton, CA) for $5 \mathrm{~s}$. The medium was removed and kept for analysis of GSH and glutathione S-transferase (15). The appearance of GSH in the medium was corrected at each time point for the contribution of lysed cells estimated by the glutathione S-transferase activity. The cell pellet was resuspended in Krebs buffer and cells were fractionated with digitonin into cytosol and particulate fractions as described before (10). GSH was determined in both fractions and was corrected by the recovery of the enzymatic activity of both compartments. Particulate fraction-associated GSH is assumed to be mitochondrial (10).

In some experiments, cells were preincubated with DEM for 20 min and then resuspended in fresh modified Fisher's medium supplemented with $1 \mathrm{mM}$ methionine and serine and the incubation continued for $3 \mathrm{~h}$ at $37^{\circ} \mathrm{C}$ under $95 \% \mathrm{O}_{2} / 5 \% \mathrm{CO}_{2}$. At different times, cells were removed for fractionation and GSH was determined in cytosol, mitochondria, and medium as described above.

Determination of cell water. The intracellular water content was determined using ${ }^{3} \mathrm{H}_{2} \mathrm{O}$ and $\left[\right.$ carboxyl $\left({ }^{14} \mathrm{C}\right]$ inulin, the latter to correct for trapped volume, as described previously (16).

Bile GSH. Rats were anesthetized with $50 \mathrm{mg} / \mathrm{kg}$ pentobarbital i.p. The abdominal cavity was opened and the bile duct was cannulated with PE 50 tubing. Bile samples were taken before and after a retrograde infusion of AT-125 into bile duct $(\sim 20 \mu \mathrm{mol} / \mathrm{kg}$ in $400 \mu \mathrm{l} / \mathrm{kg})$ to irreversibly inhibit $\gamma$-glutamyltranspeptidase $(17,18)$. Bile samples were collected directly in $40 \mathrm{mM}$ iodoacetic acid over 5-min time intervals and GSH and oxidized glutathione were quantitated by the HPLC method of Reed et al. (19).

Kinetic analyses. The kinetic model used to estimate the $V_{\max }$ and the apparent $K_{\mathrm{m}}$, as before $(12,13)$, was the Hill equation represented by: $V=V_{\max }[\mathrm{GSH}]^{n} /\left(K+[\mathrm{GSH}]^{n}\right)$, where $K_{\mathrm{m}}=\sqrt[n]{K}$ and $n$ is the number of binding or transport sites. Nonlinear least-squares fitting was done with the SAAM program (20) on an IBM 3090 (IBM, White
Table I. Efflux of Total GSH from Isolated Hepatocytes after Determination of Biliary GSH and GSSG Efflux In Vivo

\begin{tabular}{|c|c|c|c|c|c|}
\hline & & & \multicolumn{3}{|c|}{ In vivo } \\
\hline & \multirow{2}{*}{\multicolumn{2}{|c|}{ Isolated hepatocytes }} & \multicolumn{2}{|c|}{ Biliary efflux* } & \multirow[b]{3}{*}{ GSSG } \\
\hline & & & \multirow{2}{*}{$\begin{array}{l}\text { Total GSH } \\
\text { equivalents }\end{array}$} & \multirow[b]{2}{*}{ GSH } & \\
\hline & Total GSH & Total GSH efflux & & & \\
\hline & nmol $/ 10^{6}$ cells & $\mathrm{nmol} / \mathrm{min}$ per $10^{6} \mathrm{cells}$ & $\mathrm{nmol} / \mathrm{min}$ & per $g$ & \\
\hline Pair-fed & $39.0 \pm 6.0$ & $0.136 \pm 0.010$ & $3.8 \pm 1.5$ & $2.7 \pm 1.0$ & $0.5 \pm 0.2$ \\
\hline Ethanol-fed & $25.0 \pm 2.0^{\ddagger}$ & $0.173 \pm 0.012^{8}$ & $2.2 \pm 1.2$ & $1.7 \pm 0.9$ & $0.2 \pm 0.1$ \\
\hline
\end{tabular}

Results are mean \pm SD for four pair-fed controls and three ethanol-fed rats studied after 6 wk of diet.

* Biliary GSH data is after a retrograde infusion of AT-125 into the bile duct. Hepatocytes were then isolated. GSH in isolated hepatocytes was determined by the enzyme recycling assay whereas the bile was analyzed by HPLC (see Methods).

${ }^{\ddagger} P<0.025$ versus control by unpaired $t$ test.

$P<0.01$ versus control by unpaired $t$ test.

Plains, NY). A detailed discussion on selection of the appropriate kinetic model and criteria used for goodness of fit has been presented in an earlier report (13) and in the present case was the same as used previously.

Assays. Cellular, cytosolic and mitochondrial total GSH (GSH + two oxidized glutathione) content was determined after extraction with $10 \%$ trichloroacetic acid $(1: 1 \mathrm{vol} / \mathrm{vol})$ by using the method of Tietze (21). We have previously shown that $>90 \%$ of total GSH is in the reduced form in both hepatocytic compartments from control and ethanol-fed rats. GSH in bile samples was analyzed by using the HPLC method of Reed et al. (19). $\gamma$-Glutamylcysteine synthetase activity was determined according to Seelig and Meister (22), using cytosol samples after methionine preincubation so that ethanol-fed cells and pair-fed cells had the same cytosol GSH levels. In addition, the cytosol was diluted about 200 -fold in the final assay so that feedback inhibition by GSH was expected to be negligible.

\section{Results}

GSH efflux into bile in vivo. GSH and GSSG in bile samples collected in vivo were determined in pair-fed and ethanol-fed rats after inhibition of $\gamma$-glutamyltransferase, as described in Methods, to avoid degradation. After collection of bile samples, hepatocytes were isolated and the cellular content of total GSH and the efflux rate were determined. The efflux rate was increased from cells of ethanol-fed vs. pair-fed control rats despite a lower cell GSH content (Table I), confirming our previous report. However, the canalicular component of efflux from the same livers in vivo, measured before isolation, was decreased in the ethanol-fed as compared to the pair-fed although this did not reach statistical significance. In other experiments, AT- 125 was administered via the portal vein in the in situ perfused liver preparation, and no change in sinusoidal efflux was seen in either group (not shown).

Kinetics of GSH efflux from hepatocytes of pair- and ethanol-fed rats. Hepatocytes from pair-fed and ethanol-fed rats were subjected to the treatments described in Methods to obtain a wide range of cellular GSH concentrations. After cells were fractionated with the digitonin technique, it was possible to define a kinetic relationship between the total GSH efflux rate and the cytosolic GSH content for both groups (Fig. 1). The best possible fit according to previous criteria (13), repre- 


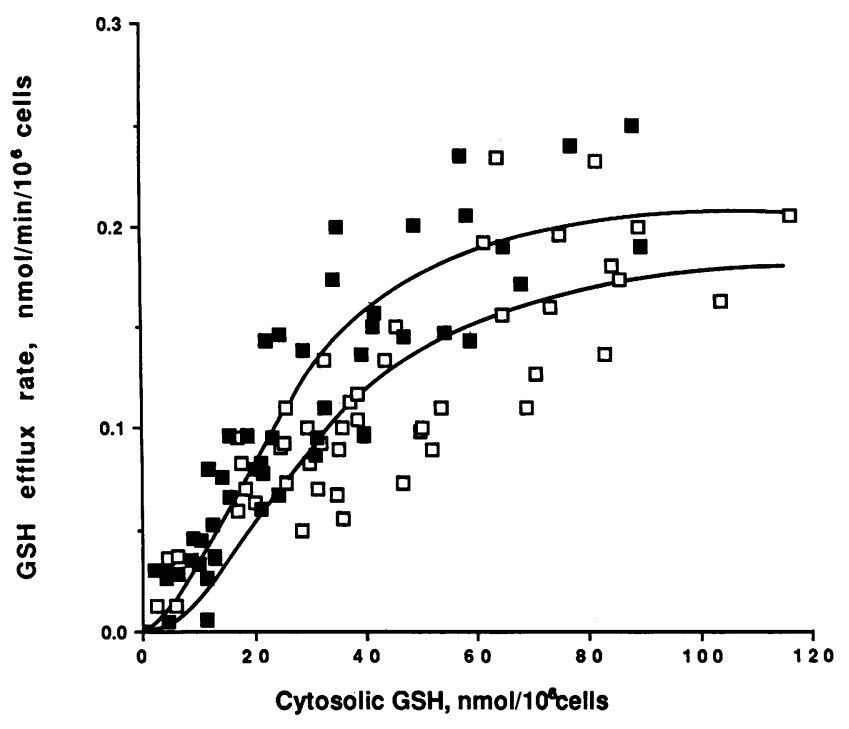

Figure 1. Comparison of the kinetics of the efflux of cytosolic GSH in hepatocytes from ethanol and pair-fed rats. Cytosolic GSH content was varied below and above control levels by preincubation with DEM or methionine and serine or after an in vivo injection of cobalt chloride. The rate of GSH efflux was determined over the course of 30-min incubation. Cells were fractionated into cytosolic and mitochondrial compartments by digitonin treatment. (ㅁ) Data from pairfed hepatocytes; ( $\square$ ) data from ethanol-fed hepatocytes. Hepatocytes were isolated from 12 pair-fed and 12 ethanol-fed rats. The continuous lines represent the fits obtained by the $\operatorname{Hill}$ model $(13,20)$.

sented by the curves in Fig. 1 was obtained using the Hill model with $n=2$. The following kinetic parameters were computed: $V_{\max }=0.22 \pm 0.013\left(\mathrm{nmol} / \mathrm{min}\right.$ per $10^{6}$ cells) for ethanol-fed and $0.20 \pm 0.014$ for pair-fed cases, which were not significantly different. However, the $K_{\mathrm{m}}$ for GSH efflux was $24 \%$ lower $(P<0.05)$ in the ethanol-fed cells versus the pairfed controls $\left(25.3 \pm 2.28\right.$ vs. $33.5 \pm 1.38 \mathrm{nmol} / 10^{6}$ cells, respectively).

Cellular water was increased as a consequence of chronic ethanol feeding versus pair-feeding ( $5.3 \pm 0.4$ vs. $4.4 \pm 0.3 \mu \mathrm{l}$ of cell water $/ 10^{6}$ cells, $P<0.02$ ). We have expressed our results as total cytosolic GSH content per $10^{6}$ cells. The increased cellular water in the ethanol-fed group indicates that the actual difference in $K_{\mathrm{m}}$ between the two groups is even greater than that shown above. We assume that the increased cell water is reflected in the same proportional increase in cytosolic water. When a correction based on the differences in the cellular water content was made to the data (Fig. 2), the $K_{\mathrm{m}}$ value for the ethanol-fed group was lower by $36 \%(P<0.05)$ in the ethanol-fed versus the pair-fed controls $(4.79 \pm 0.44$ vs. $7.53 \pm 0.84 \mathrm{nmol} / \mu \mathrm{l}$ of cell water, respectively) whereas $V_{\max }$ remained unchanged from above in both groups. In the above model-fitting attempts, to avoid systematic deviations of the fits from the data, we have had to constrain $n$ to a value equal to 2 after trying a range of values, since free adjustment of this parameter by SAAM (20) program caused unacceptable systematic deviations of the fit from the data. However, $V_{\max }$ and $K_{\mathrm{m}}$ were both allowed to adjust freely by the SAAM program to obtain estimates of the deviations reported.

Relation of mitochondrial and cytosolic GSH. Fig. 3 relates the mitochondrial to the cytosolic total GSH pool for both groups of cells. In cells from pair-fed rats, increasing cytosolic GSH was accompanied by increasing mitochondrial GSH in a

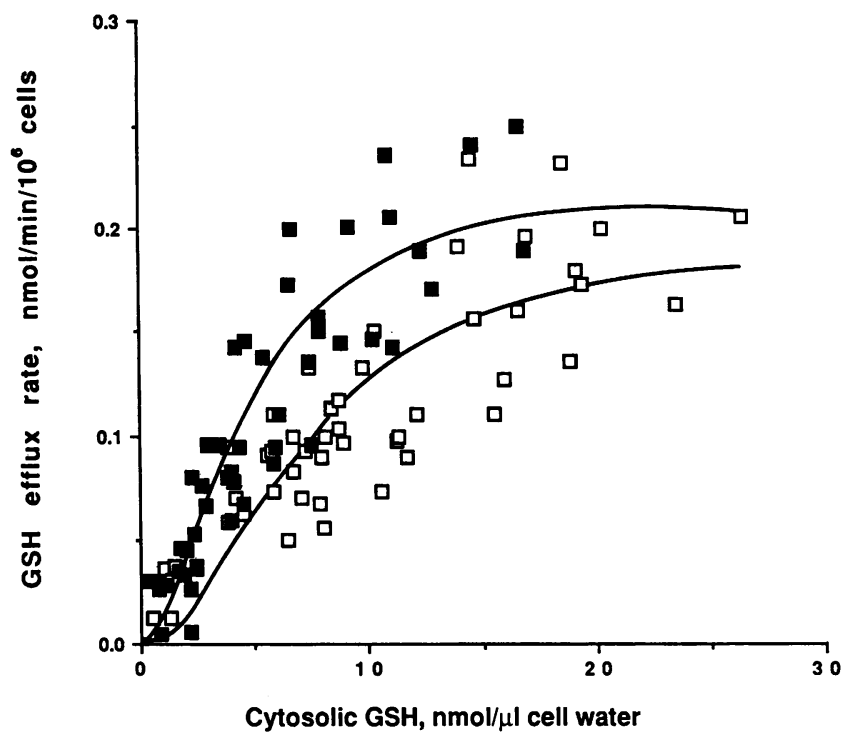

Figure 2. Comparison of the kinetics of the efflux of cytosolic GSH in hepatocytes from ethanol and pair-fed rats after correction for cell volume between the two groups. (ㅁ) Data from pair-fed hepatocytes; (a) from ethanol-fed hepatocytes. The continuous lines represent the fits obtained by the Hill model $(13,20)$.

linear relationship. The mitochondrial GSH was consistently lower in the ethanol-fed cells over the same range of cytosolic GSH. Since our previous work compared the ethanol-fed cells and controls only at the cytosol concentration found after isolation and since the cytosol concentration was lower in the

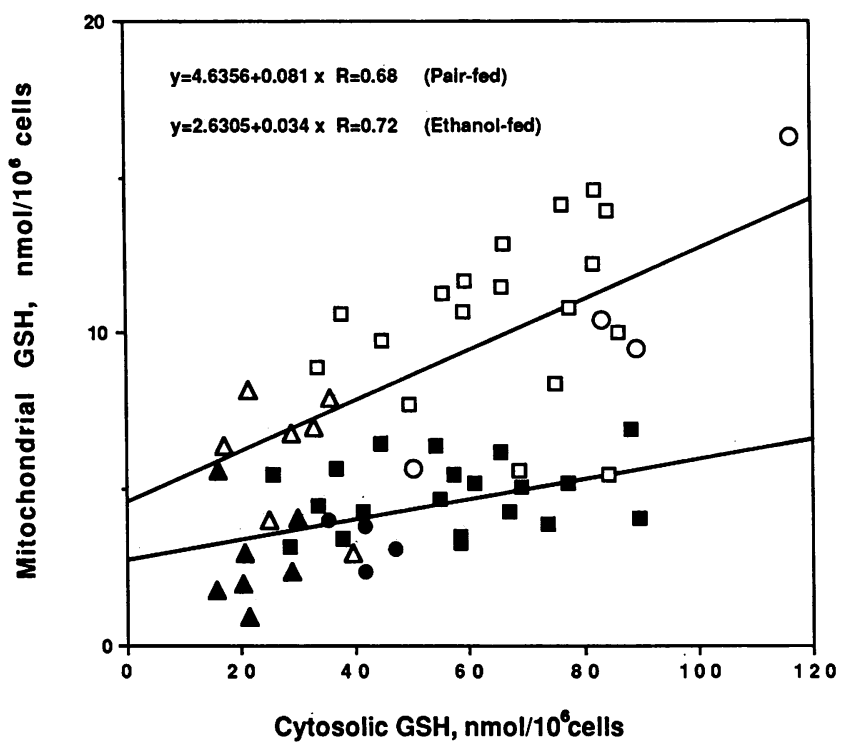

Figure 3. Relationship between cytosolic and mitochondrial GSH in hepatocytes from control and ethanol-fed rats. Hepatocytes were isolated from 15 pair-fed and 15 ethanol-fed rats. Either cobalt chloride pretreatment in vivo or incubation with methionine in vitro for 1-4 hours were used to raise GSH. Cells were fractionated (see Methods) into cytoplasmic and particulate fractions and total GSH determined. The data was fitted by linear regression. $(\Delta, \Delta)$ Untreatedcells; $(0, \bullet)$ cobalt-chloride cells; and $(\square, \square)$ methionine-preincubated cells. Open symbols represent data from pair-fed and closed ones from ethanol-fed hepatocytes. The greater number of symbols than number of animals reflects multiple incubation conditions with each group. 
Table II. Synthesis Rate of Total GSH in Hepatocytes from Pair-fed and Ethanol-fed Rats

\begin{tabular}{rcc}
\hline & \multicolumn{2}{c}{ Total GSH } \\
\cline { 2 - 3 } Time & Pair-fed & Ethanol-fed \\
\hline $\min$ & \multicolumn{3}{c}{$n$ mol $/ 10^{\circ}$ cells } \\
& $10.3 \pm 4.2$ & $10.4 \pm 7.1$ \\
30 & $35.8 \pm 7.6$ & $28.8 \pm 0.3$ \\
60 & $54.9 \pm 12.2$ & $42.3 \pm 2.2$ \\
180 & $103.2 \pm 4.4$ & $92.5 \pm 13.7$
\end{tabular}

Cells were preincubated with DEM $(0.8 \mathrm{mM})$ for $20 \mathrm{~min}$ and then resuspended in Fisher's medium with methionine and serine for $3 \mathrm{~h}$. Values represent the sum of total GSH in the cells and medium (mean $\pm \mathrm{SD}, n=3$ cell preparations from each group). The values at each time point were not significantly different.

ethanol case, interpretation was difficult; thus the present data excludes a threshold phenomenon in which mitochondrial GSH accumulates only above a certain cytosol level: Finally, the data reveal that the proportional increase in mitochondrial GSH is decreased in the ethanol-fed cells versus controls as cytosolic GSH is increased. Thus, the slope of the relation between mitochondrial and cytosolic GSH (Fig. 3) for the ethanol-fed cells is $58 \%$ of the pair-fed controls $(0.034$ vs. 0.081$)$, a difference which is highly significant $(P<0.001)$. Values for cells pretreated with DEM were not used in this analysis.

Effect of chronic ethanol administration on the rate of synthesis of cellular GSH and compartmentation. Cells from both groups were first severely depleted of GSH by preincubation with DEM, then resuspended in modified Fisher's medium with methionine and serine $(1 \mathrm{mM})$ and incubated for $3 \mathrm{~h}$ to follow resynthesis and compartmentation. Cytosolic total GSH was depleted to $\sim 8 \mathrm{nmol} / 10^{6}$ cells in both groups whereas mitochondrial GSH was $2 \mathrm{nmol} / 10^{6}$ cells in controls and $1 \mathrm{nmol} / 10^{6}$ cells in ethanol-fed cells. Viability remained $>90 \%$. The increase in total GSH in the whole incubation system (cellular [as the sum of cytosol and mitochondrial] + medium), representing net synthesis, was similar for pair-fed and ethanol-fed cells (Table II). We have previously observed no detectable degradation of extracellular GSH under these experimental conditions (10) and this point was confirmed in the present studies (not shown). In addition, the $\gamma$-glutamylcysteine synthetase activity in ethanol-fed cells was $92 \pm 5 \%$ of the activity of the pair-fed controls $(579 \pm 46$ vs. $632 \pm 102$ $\mathrm{nmol} / \mathrm{min}$ per $10^{6}$ cells; $n=4$ ). Thus, no significant decrease in the capacity to synthesize GSH from methionine was found in the ethanol-fed cells.

The ability to rapidly replete the mitochondrial pool was markedly different in cells from ethanol-treated rats compared to controls (Fig. 4). The pair-fed cells were able to increase the mitochondrial pool as the cytosolic total GSH increased. In contrast, the ethanol-fed cells maintained an almost constant and very low mitochondrial pool during the 3-h incubation in the medium supplemented with methionine and serine despite a progressive increase in cytosolic total GSH.

Time course of changes in hepatic GSH homeostasis during chronic ethanol feeding. All of the above studies and our previous work were performed after 6-8 wk of dietary treatment. To examine the rapidity of the onset and relationship of the changes in GSH homeostasis, the levels of cytosolic and mito-
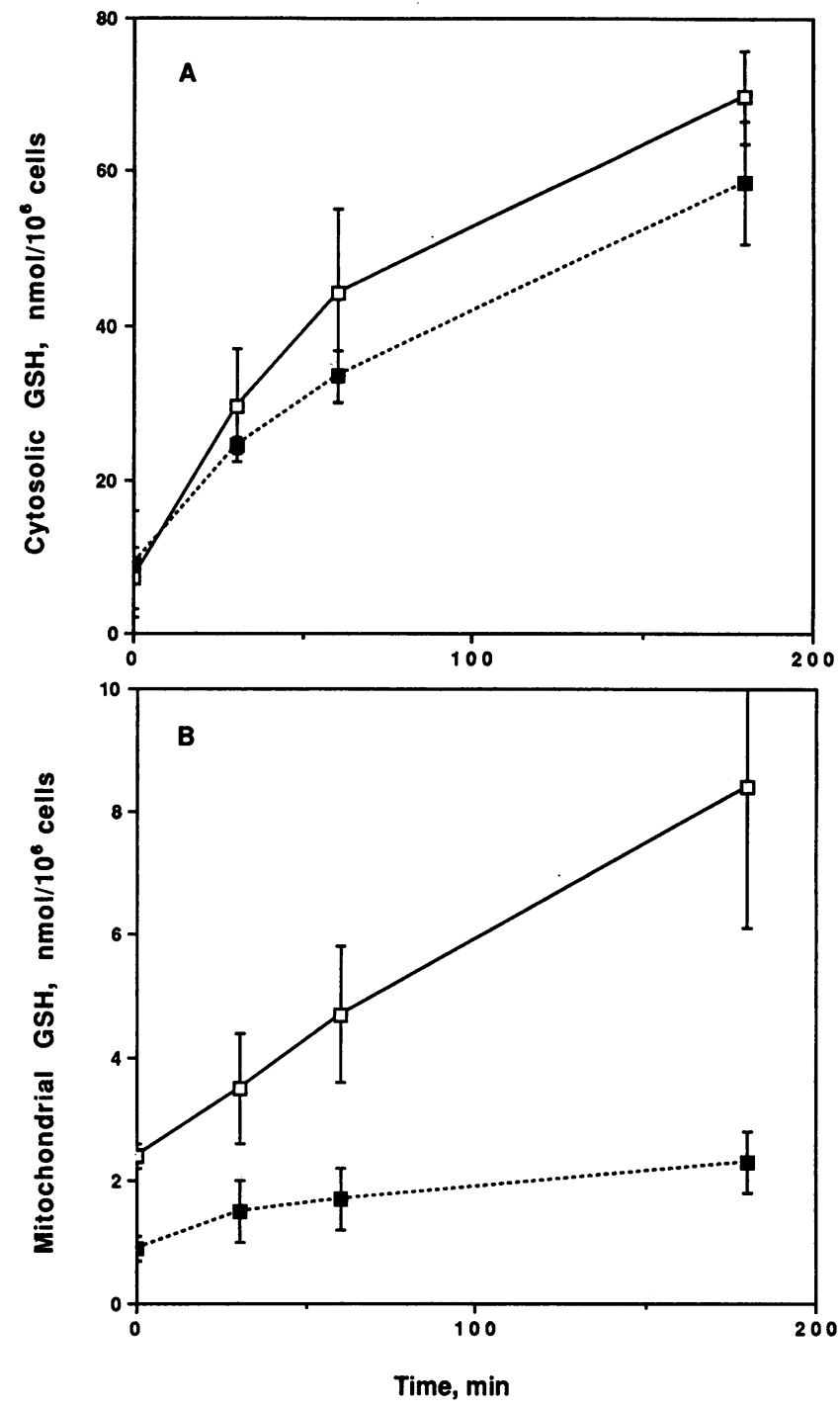

Figure 4. Comparison of the time-dependent increase in cytosolic and mitochondrial GSH during resynthesis following depletion in hepatocytes from control and ethanol-fed rats. Hepatocytes were first preincubated with diethyl maleate $(0.8 \mathrm{mM})$ for $20 \mathrm{~min}$ and then washed and resuspended in Fisher's medium and incubated with methionine and serine $(1 \mathrm{mM})$ for $3 \mathrm{~h}$. Cells were fractionated by the digitonin technique and total GSH was determined in both cytosolic and mitochondrial fractions over time from pair-fed ( $\square$ ) and ethanolfed (a) hepatocytes. (A) Cytosol GSH; (B) mitochondrial GSH, mean $\pm \mathrm{SD}$ for $n=3$ cells preparations.

chondrial total GSH and the rate of GSH efflux were determined in pair-fed and ethanol-fed cells from rats at 2 and $4 \mathrm{wk}$ of treatment (Table III). At 2 wk, a selective $50 \%$ decrease in mitochondrial GSH was observed $(P<0.01)$, without an effect on cytosolic total GSH or efflux. By 4 wk, the mitochondrial total GSH fell further while a fall in cytosolic total GSH and increased efflux were evident in the ethanol-fed group. The extent of the latter changes were similar to that which we have found after 6-8 wk of ethanol feeding (10).

\section{Discussion}

We have previously described changes in the regulation of hepatic GSH as a result of chronic ethanol feeding in rats (10). These include increased efflux in the perfused liver and iso- 
Table III. Effect of Time Course of Ethanol Feeding on Cellular Compartmentation of GSH and GSH Efflux Rate

\begin{tabular}{|c|c|c|c|c|}
\hline $\begin{array}{l}\text { Time of } \\
\text { feeding }\end{array}$ & $\begin{array}{l}\text { Cytosolic } \\
\text { total GSH }\end{array}$ & $\begin{array}{l}\text { Mitochondrial } \\
\text { total GSH }\end{array}$ & $\begin{array}{l}\text { Total GSH } \\
\text { efflux rate }\end{array}$ & Fractional efflux \\
\hline & $\mathrm{nmol} / 10^{6}$ cells & $\mathrm{nmol} / 10^{6} \mathrm{cells}$ & $\begin{array}{c}\mathrm{nmol} / \mathrm{min} \text { per } \\
10^{6} \mathrm{cells}\end{array}$ & $h^{-1}$ \\
\hline \multicolumn{5}{|l|}{2 weeks } \\
\hline Control & $41.4 \pm 1.8$ & $6.3 \pm 1.4$ & $0.176 \pm 0.045$ & $0.255 \pm 0.043$ \\
\hline Ethanol & $\begin{array}{c}39.4 \pm 9.4 \\
(95 \%)\end{array}$ & $\begin{array}{c}3.3 \pm 0.4^{*} \\
(52 \%)\end{array}$ & $\begin{array}{c}0.160 \pm 0.031 \\
(91 \%)\end{array}$ & $\begin{array}{c}0.243 \pm 0.054 \\
(95 \%)\end{array}$ \\
\hline \multicolumn{5}{|l|}{4 weeks } \\
\hline Control & $36.9 \pm 6.1$ & $5.5 \pm 0.5$ & $0.171 \pm 0.019$ & $0.278 \pm 0.065$ \\
\hline Ethanol & $\begin{array}{c}25.9 \pm 5.1^{\ddagger} \\
(70 \%)\end{array}$ & $\begin{array}{c}2.1 \pm 0.9^{8} \\
(38 \%)\end{array}$ & $\begin{array}{c}0.210 \pm 0.029^{\prime \prime} \\
(123 \%)\end{array}$ & $\begin{array}{c}0.486 \pm 0.044^{\S} \\
(175 \%)\end{array}$ \\
\hline
\end{tabular}

Results are mean \pm SD of $n=5$ cell preparations for each group of animals at each time. Data in parentheses represent the percentage of control.

* $P<0.005$ versus pair-fed by unpaired $t$ test.

${ }^{\ddagger} P<0.025$ versus pair-fed by unpaired $t$ test.

${ }^{8} P<0.001$ versus pair-fed by unpaired $t$ test.

" $P<0.05$ versus pair-fed by unpaired $t$ test.

lated hepatocytes and moderately decreased cytosolic and markedly diminished mitochondrial GSH pools. Our current studies have further characterized the basis for these reported changes.

The enhanced hepatic GSH efflux in the ethanol-fed case was previously observed in the caval perfusate of the perfused liver by Pierson and Mitchell (23) and by us (10). We also observed increased efflux from hepatocytes isolated from ethanol-fed rats (10). Since a significant component of GSH efflux from the liver is into bile (24), it was of interest to determine whether the effect of ethanol is specific for the sinusoidal pole. In the present studies, we have found that bile GSH efflux is not increased from the liver of ethanol-fed rats under conditions in which $\gamma$-glutamyltranspeptidase is inhibited. In fact, efflux into bile was somewhat decreased, which may be explained by the lower GSH content of the liver (24). Thus, it is reasonable to conclude that the enhanced efflux observed in isolated hepatocytes is accounted for by an effect of ethanol feeding on the sinusoidal efflux as seen in the intact liver.

We previously found that efflux from isolated hepatocytes from ethanol-fed rats was increased despite a lower cytosolic GSH content. In the present studies we have examined the kinetics of efflux. To accomplish this, we have raised and lowered cytosolic GSH over a wide range. In all our previous studies we have related efflux to changes in total cell GSH. However, we have for the first time related efflux just to cytosolic GSH content, the pool specifically available for efflux. In pair-fed cells the $K_{\mathrm{m}}$ and $V_{\max }$ for efflux were similar to our previous reports $(12,13)$. The major difference from our previous reports is that two rather than the previously reported three interactive sites $(12,13)$ best describe the kinetics when applying the Hill model. The explanation for this difference remains to be clarified. However, it should be stressed that the dietary treatment of the rats in the present studies differs from our previous work as does the use of the digitonin fractionation to determine directly the cytosol GSH content. Moreover, the use of the Hill model is simply an utility model to extract $K_{\mathrm{m}}$ and $V_{\max }$ values from our data as extensively discussed before $(12,13)$. As for the increased efflux in hepatocytes from ethanol-fed rats, we considered an increase in $V_{\max }$ owing to induction of transporters in the sinusoidal membrane as one possibility. Thus, if the lowered cytosolic GSH in the ethanol-fed cell relative to pair-fed controls were raised to the levels of the latter, or higher, the difference in efflux between ethanol and control cells would be expected to become even greater. This was not the case. Both control and ethanol-fed cells reached a similar $V_{\max }$ but exhibited different $K_{\mathrm{m}}$, ethanol-fed cells being $75 \%$ of controls. Thus, at concentrations of cytosolic GSH below saturation, efflux from ethanol-fed cells was greater than from controls. Cellular water content was $20 \%$ higher in the ethanol-fed cells. Thus, in comparing ethanol-fed to control, the concentration of GSH is slightly more dilute than in the control case. When this factor is taken into account, the $K_{\mathrm{m}}$ of ethanol-fed cells decreases to $64 \%$ of the controls, an even greater difference. The control $K_{\mathrm{m}}$ value of about $7.5 \mathrm{mM}$ for cytosolic GSH may seem unexpectedly high. However, liver GSH levels of 5-6 $\mu \mathrm{mol} / \mathrm{g}$ liver translate into cytosolic GSH level in the $8-10 \mathrm{mM}$ range $(\sim 60 \%$ of wet weight of liver is intracellular water [13]).

The mechanism for this change in $K_{\mathrm{m}}$ is not known. The possibilities include decreased availability of an endogenous competitive inhibitor whose effect would raise the $K_{\mathrm{m}}$ or an effect on membrane lipid composition or fluidity. It is possible that this adaptation to chronic ethanol exposure is of advantage in insuring the maintenance of plasma GSH for utilization by extrahepatic tissue despite the fall in cytosolic GSH.

The fall in cytosolic GSH in the chronic ethanol case does not seem to be caused by a limitation in the capacity to synthesize GSH. Thus, $\gamma$-glutamylcysteine synthetase activity, which is the rate-limiting enzymatic step in GSH synthesis, was minimally affected by ethanol feeding. After depleting GSH, we examined the rate of its resynthesis in the presence of unlimited methionine and serine, the former to provide cysteine via transsulfuration and the latter to insure its availability for transsulfuration. The rate of synthesis was not significantly different between the two groups. This indicates that in the face of abundant precursors, the capacity of both the transsulfuration pathway and GSH biosynthetic pathways were relatively unaffected by chronic ethanol exposure. Also, this indicates that ATP required for GSH synthesis was not limiting. Thus, the fall in cytosol GSH in chronic ethanol-fed liver cannot be attributed to an effect on the capacity for synthesis. Rather it would appear to be due to a combination of increased efflux at cytosolic GSH levels below $V_{\max }$ concentrations ( $<50 \mathrm{nmol} / 10^{6}$ cells) and presumed limitation on availability of precursors in vivo to maintain synthesis of GSH needed to keep up with efflux. The latter could be due to impaired transsulfuration as a consequence of the known decreased serine synthesis in ethanol-fed livers (25), alterations in intracellular cysteine homeostasis leading to lowered cysteine availability for GSH synthesis, or impaired uptake of sulfur amino acids by hepatocytes. Further work will be required to distinguish between these three possibilities.

Mitochondrial GSH is vital for cellular defense against endogenous or exogenous oxidant stress. Complete depletion of mitochondrial GSH is followed by gradual loss of cell viability (26), although there is some controversy about this (27). When hepatocytes are exposed to exogenous oxidant stress, cell death occurs only after complete depletion of mitochondrial GSH (1, 26). GSH is not synthesized in mitochondria and there appears to be rapid equilibration of newly synthesized GSH between cytosol and mitochondria (2). Controversy exists as to whether turnover of GSH in mitochondria does or does not occur at a slower rate than in cytosol $(2,26)$. However, GSH appears to 
be slowly released from mitochondria when the cytosolic GSH is depleted (26).

We have examined the relationship between cytosolic and mitochondrial GSH over a wide range. There is no prior published work on the relationship between the size of these two pools. In controls, as cytosolic GSH was raised, mitochondrial GSH increased linearly. In the ethanol case, a significantly lower slope for this relationship was observed. This suggests that there is an impairment in either the uptake or retention of GSH in these mitochondria. To demonstrate this further, we severely depleted cytosolic and mitochondrial GSH in isolated hepatocytes and followed the time-dependent repletion of mitochondrial GSH in the face of maximum GSH resynthesis in cytosol. The resynthesis of GSH in the two groups, as noted above, was similar. In controls, a progressive increase in mitochondrial GSH paralleled the increase in cytosol GSH. In striking contrast, mitochondrial GSH did not increase in the ethanol-fed cells despite a similar rise in cytosolic GSH. Thus, our findings further define a potentially critical defect in sequestration of mitochondrial GSH. In addition, the data suggest that therapy designed to raise cytosolic GSH may not correct at least acutely the deficiency in mitochondrial GSH in chronic alcoholism.

Much attention has focused on oxidant stress and the possible role of lipid peroxidation in the pathogenesis of alcoholic liver disease. The defect in sequestration of mitochondrial GSH could play a key role in increasing the susceptibility to cell injury from the normal endogenous oxidant stress in hepatocytes or from even minimally enhanced oxidant stress as a result of acetaldehyde oxidation by aldehyde oxidase or xanthine oxidase or release of oxyradicals from activated phagocytic cells in the vicinity of hepatocytes.

\section{Acknowledgments}

Assistance of Dr. Irving Lyon in the perfused liver studies is gratefully acknowledged.

This work was supported by National Institutes of Health grant DK-30312, Veterans Administration Medical Research funds, and gifts from Pfizer, Inc. and the United Liver Association. Dr. Fernandez-Checa was a recipient of fellowship awards from the American Liver Foundation and Smith-Kline-Beckman.

\section{References}

1. Meredith, M. J., and D. J. Reed. 1983. Depletion in vitro of mitochondrial glutathione in rat hepatocytes and enhancement of lipid peroxidation by adriamycin and 1,3-bis(2-chloroethyl)-1-nitrosourea (BCNU). Biochem. Pharmacol. 32:1383-1388.

2. Griffith, O. W., and A. Meister. 1985. Origin and turnover of mitochondrial glutathione. Proc. Natl. Acad. Sci. USA. 82:4668-4672.

3. Ookhtens, M., I. Lyon, J. C. Fernandez-Checa, and N. Kaplowitz. 1988. Inhibition of glutathione efflux in the perfused rat liver and isolated hepatocytes by organic anions and bilirubin: kinetics, sidedness and molecular forms. J. Clin. Invest. 82:608-616.

4. Aw, T. Y., M. Ookhtens, and N. Kaplowitz. 1984. Inhibition of glutathione efflux from isolated rat hepatocytes by methionine. J. Biol. Chem. 259:9355-9358.

5. Aw, T. Y., M. Ookhtens, and N. Kaplowitz. 1986. Mechanism of inhibition of glutathione efflux by methionine from isolated rat hepatocytes. Am. J. Physiol. 251:G354-G361.

6. Aw, T. Y., M. Ookhtens, J. F. Kuhlenkamp, and N. Kaplowitz. 1987. Trans-stimulation and driving forces for GSH transport in sinusoidal vesicles from rat liver. Biochem. Biophys. Res. Commun. 143:377-382.

7. Shaw, S., E. Jayatilleke, W. A. Ross, E. R. Gordon, and C. S.
Lieber. 1981. Ethanol-induced lipid peroxidation: potentiation by long term alcohol feeding and attenuation by methionine. J. Lab. Clin. Med. 98:417-424.

8. Boveris, A., C. G. Fraga, A. I. Varsavsky, and O. R. Koch. 1983. Increased chemiluminescence and superoxide production in the liver of chronically ethanol-treated rats. Arch. Biochem. Biophys. 227:534541.

9. Reed, D. J. 1986. Regulation of reductive processes by glutathione. Biochem. Pharmacol. 35:7-13.

10. Fernandez-Checa, J. C., M. Ookhtens, and N. Kaplowitz. 1987. Effect of chronic ethanol feeding on rat hepatocytic glutathione: compartmentation, efflux and response to incubation with ethanol. J. Clin. Invest. 80:57-62.

11. DeCarli, L. M., and C. S. Lieber. 1967. Fatty liver in the rat after prolonged intake of ethanol with a nutritionally adequate new liquid diet. J. Nutr. 91:131-138.

12. Aw, T. Y., M. Ookhtens, C. Ren, and N. Kaplowitz. 1986. Kinetics of glutathione efflux from isolated rat hepatocytes. Am. J. Physiol. 250:G236-G243.

13. Ookhtens, M., K. Hodby, M. C. Corvasce, T. Y. Aw, and N. Kaplowitz. 1985. Sinusoidal efflux of glutathione in the perfused rat liver: evidence for a carrier-mediated process. J. Clin. Invest. 75:258265.

14. Moldeus, P., T. Hogberg, and S. Orrenius. 1978. Isolation and use of liver cells. Methods Enzymol. 51:60-70.

15. Booth, J. B., E. Boyland, and P. Sims. 1961. An enzyme from rat liver catalyzing conjugations with glutathione. Biochem. $J$. 79:516-524.

16. Fernandez-Checa, J. C., C. Ren, T. Y. Aw, M. Ookhtens, and N. Kaplowitz. 1988. Effect of membrane potential and cellular ATP on glutathione efflux from isolated rat hepatocytes. Am. J. Physiol. 255:G403-G408.

17. Ballatori, N., R. Jacob, and Boyer, J. L. 1986. Intrabiliary glutathione hydrolysis: a source of glutamate in bile. J. Biol. Chem. 261:7860-7865.

18. Abbott, W. A., and A. Meister. 1986. Intrahepatic transport and utilization of biliary glutathione and its metabolites. Proc. Natl. Acad. Sci. USA. 83:1246-1250.

19. Reed, D. J., J. R. Babson, P. W. Beatty, A. E. Brodie, W. W. Ellis, and D. W. Potter. 1980. High-performance liquid chromatography analysis of nanomole levels of glutathione, glutathione disulfide and related thiols and disulfides. Anal. Biochem. 106:55-62.

20. Berman, M., and M. F. Weiss. 1977. SAAM Manual. Publication No. 76-730. Department of Health, Education and Welfare, National Institutes of Health, Government Printing Office, Washington, DC.

21. Tietze, F. 1969. Enzymic method for quantitative determination of nanogram amounts of total and oxidized glutathione: applications to mammalian blood and other tissues. Anal. Biochem. 27:502522.

22. Seelig, G. F., and A. Meister. 1984. $\gamma$-Glutamylcysteine synthetase from erythrocytes. Anal. Biochem. 141:510-514.

23. Pierson, J. L., and M. C. Mitchell. 1986. Increased hepatic efflux of glutathione after chronic ethanol feeding. Biochem. Pharmacol. 35:1533-1537.

24. Kaplowitz, N., D. Eberle, J. Petrini, J. Touloukian, M. Corvasce, and J. Kuhlenkamp. 1983. Factors influencing the efflux of hepatic glutathione into bile in rats. J. Pharmacol. Exp. Ther. 224:141-147.

25. LaBaume, L. B., D. K. Merrill, G. L. Clary, and R. W. Guynn. 1987. Effect of acute ethanol on serine biosynthesis in liver. Arch. Biochem. Biophys. 256:569-577.

26. Meredith, M. J., and D. J. Reed. 1982. Status of the mitochondrial pool of glutathione in the isolated hepatocyte. J. Biol. Chem. 257:3747-3753.

27. Ku, R. H., and R. E. Billing. 1986. The role of mitochondrial glutathione and cellular protein sulfhydryls in formaldehyde toxicity in glutathione-depleted rat hepatocytes. Arch. Biochem. Biophys. 247:183-189. 